\title{
$O$ enfoque ético no gerenciamento de resultados
}

\section{Ethical focus on management results}

\section{Marleide Cerqueira de Oliveira}

Mestre em Ciências Contábeis pela Universidade Federal de Minas Gerais

Coordenadora dos cursos de Ciências Contábeis e Gestão Financeira da Faculdade Pitágoras

Endereço: Av. Prudente de Morais, no 1602

CEP: 30380-650 - Belo Horizonte - MG - Brasil

E-mail: marleide478@ hotmail.com

Telefone: (31) 3055-1062

\section{Vagner Antonio Marques}

Doutorando em Administração e Mestre em Ciências Contábeis pela Universidade Federal de Minas Gerais

Professor Assistente do Departamento de Ciências Contábeis da PUC Minas

Endereço: Av. Antonio Carlos, no 6627

CEP: 31270-901 - Belo Horizonte - MG - Brasil

E-mail: vmarques@pucminas.br

Telefone: (31) 3409-7275

\section{Jacqueline Veneroso Alves da Cunha}

Doutora em Ciências Contábeis pela Universidade de São Paulo

Professora Adjunta do Curso de Ciências Contábeis da Universidade Federal de Minas Gerais Endereço: Av. Antonio Carlos, no 6627

CEP: 31270-901 - Belo Horizonte - MG - Brasil

E-mail: jvac@face.ufmg.br

Telefone: (31) 3409-7275

\section{Poueri do Carmo Mario}

Doutor em Ciências Contábeis pela Universidade de São Paulo

Professor Adjunto do Curso de Ciências Contábeis da Universidade Federal de Minas Gerais Endereço: Av. Antonio Carlos, no 6627

CEP: 31270-901 - Belo Horizonte - MG - Brasil

E-mail: poeri@face.ufmg.br

Telefone: (31) 3409-7277

Artigo recebido em 13/09/2010. Revisado por pares em 01/10/2012. Reformulado em 01/11/2012. Recomendado para publicação em 12/11/2012 por Sandra Rolim Ensslin (Editora Científica). Publicado em 14/12/2012. 


\title{
Resumo
}

No mundo ideal, as decisões sobre o nível de divulgação das demonstrações contábeis seriam baseadas no aumento do bem estar social dos indivíduos. Porém, isso não ocorre porque os diversos agentes econômicos não possuem a mesma informação, em termos de quantidade e/ou qualidade. Neste contexto, surge a seguinte questão de pesquisa: o gerenciamento de resultados representa uma prática ética? Assim, este artigo tem como objetivo analisar o julgamento de alunos do curso de mestrado em Ciências Contábeis em relação ao gerenciamento de resultados. $\mathrm{Na}$ análise dos dados coletados, nenhuma prática foi unanimente julgada como ética ou antiética.

Palavras-chave: Gerenciamento de resultado. Ética. Características qualitativas.

\begin{abstract}
In the ideal world, decisions about the level of disclosure of financial statements would be based on increasing the welfare of individuals. However, this does not occur because the diverse economic agents do not possess the same information, in terms of amount and/or quality. In this context arises the following research question: earnings management is an ethical practice? Thus, this article aims to analyze the judgment of students of Masters of Sciences in Accounting in relation to earnings management. In analyzing the data collected, no practice was unanimously judged as ethical or unethical.
\end{abstract}

Keywords: Management of result. Ethics. Qualitative characteristics.

\section{Introdução}

O principal objetivo da divulgação das informações financeiras é auxiliar os investidores e demais usuários na tomada de decisões. Iudícibus (2004, p.25) afirma que "o objetivo básico da contabilidade, [...] pode ser resumido no fornecimento de informações econômicas para vários usuários, de forma que propiciem decisões racionais". Desta forma, os usuários das informações financeiras necessitam que tais ferramentas sejam dotadas de transparência, para que possam ser confiáveis.

Contudo, em virtude da flexibilidade da regulamentação contábil, os gestores podem adotar diferentes critérios aceitos para registro dos procedimentos contábeis, exercendo certa discricionariedade. Segundo Hendriksen e Van Breda (2009), existem padrões contábeis determinados por autoridades regulamentadoras e outros que são determinados pela própria empresa, que incluem os métodos que a administração da entidade julga serem os mais apropriados para apresentar adequadamente a posição financeira, as mudanças de posição financeira, e os resultados das operações de acordo com Princípios Contábeis geralmente aceitos e que tenham sido utilizados para elaborar as demonstrações financeiras. Para os usuários externos, os motivos que levaram à adoção de tais métodos não são evidenciados, pois as informações contábeis sofrem influência dos interesses pessoais dos administradores 
ou agentes, com o objetivo de evidenciar o desempenho ou a estrutura financeira da empresa da forma desejada.

Isso ocorre porque os diversos agentes econômicos não possuem a mesma informação, em termos de quantidade e/ou qualidade. Scott apud Paulo e Martins (2007) explica que "freqüentemente, um tipo de participante no mercado (vendedor, por exemplo) conhecerá algo a mais sobre o ativo que está sendo negociado que outro tipo de participante (comprador) não sabe", o que é denominado de assimetria informacional. De forma mais ampla, Hendriksen e Van Breda (2009, p.139), definem assimetria informacional "quando nem todos os estados são conhecidos por ambas as partes e, assim, certas conseqüências não são por elas consideradas".

Um dos principais papéis da Contabilidade está na redução da assimetria informacional, minimizando os conflitos de agência e, conseqüentemente, contribuindo para a adequada alocação dos recursos disponíveis. Em sua Estrutura Conceitual Básica, ao nível de normas internacionais (IASB), Hendriksen e Van Breda (2009) afirmam que características qualitativas das demonstrações contábeis devem estar presentes para que as informações sejam úteis aos usuários.

Neste contexto, uma vez que gerenciar resultados está sendo cada vez mais explorado e pesquisado, surge a seguinte questão de pesquisa: o gerenciamento de resultados representa uma prática ética?

Assim, o presente artigo tem como objetivo analisar o julgamento de alunos do curso de mestrado em Ciências Contábeis em relação ao gerenciamento de resultados (earnings management) uma vez que são estes os futuros divulgadores do conhecimento contábil.

Buscando atender a um mercado cada vez mais competitivo e ávido por lucratividade, a Contabilidade evoluiu, influenciando mundialmente decisões econômicas e necessitando de profissionais que exerçam o discernimento necessário para uma tomada de decisão ética.

A manipulação dos resultados financeiros faz com que grandes empresas, conforme suas necessidades individuais, divulguem números irreais ao mercado. Mussolini (1994, p.79) afirma que "o contador deve se conscientizar de que a valorização se fundamenta, essencialmente, em dois pontos básicos: indiscutível capacidade técnica e irrepreensível comportamento ético".

Desta forma, o presente trabalho se justifica pela contribuição para uma avaliação sobre a ética dentro da Contabilidade, despertando o interesse de educadores, estudantes e demais profissionais contábeis, no sentido de expandir as pesquisas existentes sobre gerenciamento de resultados.

$\mathrm{Na}$ primeira parte do artigo será feita uma revisão bibliográfica sobre gerenciamento de resultados, accruals, comportamento ético nas informações contábeis e características qualitativas das informações contábeis. Logo após será feita uma explanação sobre a metodologia utilizada para alcançar o objetivo determinado. E por fim, será analisado o resultado da pesquisa.

\section{Referencial Teórico}

\subsection{Gerenciamento de Resultados}


Segundo Hendriksen e Van Breda (2009, p.89) "o principal objetivo da divulgação de informações financeiras é apoiar os acionistas e outros indivíduos na tomada de decisões financeiras, ajudando-os a predizer os fluxos de caixa da empresa".

Para Iudícibus e Lopes (2004), a teoria positiva da contabilidade procura descrever como as empresas decidem que tipo de informação devem divulgar, isto é, de que maneira selecionam os procedimentos contábeis que utilizam. Para esclarecer esta questão, é conhecido que os indivíduos agem basicamente em função de interesses pessoais, procurando maximizar seu bem-estar.

$\mathrm{Na}$ contabilidade, mais propriamente nas normas das práticas contábeis, é possível que o gestor opte por critérios contábeis ao longo do tempo, exercendo certa discricionariedade. Segundo Hendriksen e Van Breda (2009), a maneira pela qual uma empresa divulga sua situação financeira forma o que se chama de política contábil. Algumas políticas são determinadas por autoridades regulamentadoras e outras são determinadas pela própria empresa. Segundo a CVM (CVM/SNC/SEP N ${ }^{\circ}$ 01/2007) alguns aspectos da escolha de práticas de contabilização e divulgação de informações devem ser destacados para os administradores e contadores responsáveis pelos relatórios corporativos das companhias. Os dois aspectos a serem considerados são o conjunto de normas que orientam as companhias abertas na preparação e divulgação de suas informações contábeis e a política contábil construída a partir das escolhas feitas na prática contábil ao tratar da contabilização dos diversos tipos de transações e da divulgação dos relatórios contábeis. O primeiro aspecto trata do cumprimento das normas contábeis aprovadas pela CVM, que determinam uma estrutura mínima sobre as quais são estabelecidas as políticas contábeis da companhia. Estas normas estão referidas nos pronunciamentos aprovados pela CVM e que tomam como referência o conjunto de pronunciamentos internacionais.

O segundo aspecto trata da responsabilidade da empresa na formulação de políticas contábeis. A determinação de cumprir certas políticas contábeis estabelece uma relação de confiança com o público investidor e constrói um marco mais sólido nos atos de governança da empresa. Em um nível mais elevado, a companhia pode se valer de um comitê especializado para analisar certas questões em profundidade, notadamente em tópicos que permitem ampla margem de escolha e subjetividade no seu tratamento.

Lopes e Martins (2005) argumentam que a contabilidade pode ser usada pelos gestores com a finalidade de realizar uma comunicação seletiva dos aspectos mais interessantes do comportamento da empresa. Essa comunicação é seletiva porque os gestores não fornecem todas as informações ao seu dispor, eles selecionam aquelas mais convenientes aos seus interesses.

Martinez (2001) afirma que um dos produtos mais importantes da contabilidade para os diversos usuários da informação contábil é o resultado da empresa e o seu desempenho é, por vezes, medido por este resultado. Porém, em virtude da inserção da empresa em um mercado suscetível a fatores externos, surge a necessidade de gerenciamento deste resultado, com a finalidade de atingir um determinado objetivo. Ou seja, diante de possibilidades aceitas pela teoria contábil, haverá o risco de que os resultados obtidos pela gestão não estejam representados fielmente nos moldes aos usuários da informação contábil. O mesmo autor caracteriza o gerenciamento de resultados contábeis como alteração proposital dos resultados contábeis visando atender motivação particular. A gestão maneja artificialmente os resultados com propósitos bem definidos, que não são os de expressar a realidade latente do negócio.

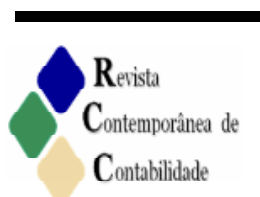


Para Schipper (1989), o gerenciamento de resultados pode ser definido como uma intervenção proposital no processo de elaboração das demonstrações financeiras externas, com a intenção de obter algum benefício particular. Outra definição freqüentemente citada nas pesquisas sobre gerenciamento de resultados contábeis foi apresentada por Healy e Wahlen (1999, p.368):

\begin{abstract}
Gerenciamento da informação contábil ocorre quando os administradores usam do julgamento na divulgação de relatórios financeiros e na estruturação de transações para alterar os relatórios financeiros, a fim de enganar alguns agentes sobre o desempenho econômico latente da companhia ou para influenciar os resultados contratuais que dependem dos números contábeis.
\end{abstract}

Segundo Martinez (2001) de acordo com as motivações envolvidas podem existir várias modalidades de gerenciamento dos resultados contábeis (earnings management), entre as quais caberia destacar:

- Gerenciamento dos resultados contábeis para aumentar ou diminuir os lucros. Os resultados são gerenciados de modo a atingir determinadas metas de referência que podem ser acima ou abaixo do resultado do período;

- Gerenciamento dos resultados contábeis para reduzir suas variabilidades (Income Smoothing). Trata-se de um procedimento que visa diminuir as possíveis flutuações do lucro para estabilizá-lo ao longo do tempo. Para corroborar com este conceito, Hendriksen e Van Breda (2009) afirmam que quanto mais volátil o lucro, mais forte a percepção de risco dos investidores;

- Gerenciamento dos resultados contábeis para reduzir lucros correntes em prol de lucros futuros.

O gerenciamento de resultados compromete a qualidade das informações contidas nas demonstrações financeiras, interferindo no processo de alocação de recursos na economia e inflige sérios prejuízos para o mercado de capitais (SANCOVSCHI; MATOS, 2003)

\title{
2.2 Trabalhos já realizados sobre o tema
}

Internacionalmente, os trabalhos mais citados apresentam modelos para proxies das acumulações discricionárias, ou seja, modelos que fornecem estimativas dos valores destas acumulações (JONES, 1991; DECHOW; SLOAN; SWEENEY, 1995; KANG; SIVARAMAKRISHNAN, 1995).

Nacionalmente, o estudo de Martinez (2001) teve o objetivo principal de demonstrar empiricamente que as companhias abertas brasileiras "gerenciam" os seus resultados contábeis como resposta a estímulos do mercado de capitais.

Sancovschi e Matos (2003) realizaram um estudo de caso, buscando avaliar quais incentivos os administradores tinham para gerenciar resultados.

O trabalho de Cupertino (2004) teve o objetivo de investigar a gestão de lucros do Banco Nacional, tanto em seus aspectos motivadores, quando em relação aos seus efeitos na composição patrimonial.

Torres et al. (2010) analisaram a associação entre o income smoothing, a estrutura de propriedade, controle e o nível de governança. Para a realização do estudo utilizaram dados de 266 empresas que comercializavam ações na BOVESPA. Os resultados indicaram forte 
associação entre o a estrutura de propriedade, controle e nível de governança com o alisamento de resultados. Observou-se que as empresas com estruturas de propriedade e controle mais concentradas tendem a alisar os resultados com maior frequência.

Os trabalhos realizados sobre o tema, usualmente testam empiricamente modelos para detecção de gerenciamento de resultados, desconsiderando os aspectos éticos envolvidos, entretanto Ackers, Giacomino e Bellovary (2007) destacam que a despeito de essa prática não contrariar aspectos legais, podem em alguns casos classificarem-se como imorais ou antiéticas. Nesse sentido, as discussões sobre o julgamento dos estudantes de pós-graduação sobre os aspectos éticos envolvidos, possibilitam iniciar as discussões sobre a questão, haja vista que estes, serão os possíveis replicadores de interpretações e valores socialmente construídos.

\subsection{Accruals}

O regime de competência é um dos principais alicerces da contabilidade e com sua observância apura-se o lucro líquido do período. De acordo com o princípio de competência as receitas e despesas deverão ser reconhecidas no momento de sua realização, independente de entradas ou saídas de recursos financeiros. Desta forma, servem de base para a mensuração do desempenho da empresa.

De acordo com Lopes e Martins (2005) o regime de competência está vinculado ao evento econômico e não ao fluxo financeiro de recebimentos e pagamentos. Em função disso, ocorrem diferenças entre o resultado econômico e o fluxo de caixa da empresa. A essas diferenças dá-se o nome de accruals.

Accrual pode ser traduzido por "acréscimo, acumulação". Porém, conforme Colauto e Beuren (2004, p.6) "se trata de adicionar valores positivos e/ou negativos, de modo a gerar aumentos ou diminuições no lucro, e não tão somente no sentido de aumento".

Segundo Nardi (2008, p.24) "o accrual contábil faz uso de apropriações, diferimento e atribuição de procedimentos, com o objetivo de relacionar receitas, despesas, ganhos e perdas aos períodos, de forma a refletir um desempenho da entidade durante um período". Para Rodrigues (2008) os accruals representam os saldos das contas de resultado que compõem a apuração do lucro ou prejuízo, mas não movimentam o disponível da empresa em função do princípio da competência. Pode-se concluir que este termo representa a diferença entre o lucro líquido e o fluxo de caixa operacional.

Para Dechow e Dichev (2002) o sistema contábil resolve o problema de alocação intertemporal nos fluxos de caixa adicionando os accruals. As mesmas autoras definem a relação entre o lucro $(E A R N)$, accruals e fluxo de caixa $(\mathrm{CF})$ da seguinte forma:

$$
\mathrm{EARN}=\mathrm{CF}+\text { accruals } \longrightarrow \text { Accruals }=\mathrm{EARN}-\mathrm{CF}
$$

Quando se fala em acumulações (accruals), têm-se acumulações circulantes e não circulantes. As circulantes são aquelas contas de resultado que possuem como contrapartida contas no ativo ou passivo circulante. Já as acumulações não circulantes, são contas de resultado com contrapartida em contas não circulantes. A classificação entre circulante e não circulante diz respeito ao prazo de realização e, mais recentemente, sobre a natureza operacional e financeira.

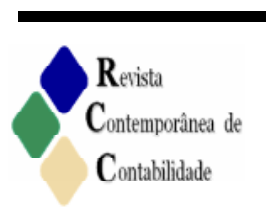


Os accruals também são categorizados em discricionários (discretionary accruals) e não discricionários (non discretionary accruals). Conforme Martinez (2001), os primeiros são inerentes às práticas de gerenciamento, ou seja, único propósito de gerenciar o resultado contábil. Os segundos se referem às atividades da empresa de acordo com a realidade do negócio. O mesmo autor relata que nada de errado existe no registro de acumulações, na verdade o intuito é mensurar o lucro no seu sentido econômico, aquele que representa acréscimo efetivo na riqueza patrimonial da unidade econômica, independente da movimentação financeira. O problema está no fato de o gestor discricionariamente aumentar ou diminuir essas acumulações (accruals) com o objetivo de influenciar o lucro.

Para Formigoni et al. (2007, p. 5), "os accruals podem ser classificados em accruals não-discricionários, que são aqueles inerentes às atividades da empresa, ou em accruals discricionários, que são aqueles artificiais e teriam como objetivo somente manipular o resultado contábil".

Os accruals, em função das estimativas, necessitam de ajustes futuros de correção quando se conhece o valor exato, no momento da realização financeira. Um exemplo disso são as provisões que buscam corrigir valores contabilizados com o objetivo de ajustá-los ao valor de realização.

\subsection{Comportamento ético na informação contábil}

Dentro de um contexto atual, com a internacionalização dos processos produtivos, bem como a dos mercados financeiro e comercial, a informação passa a ser uma ferramenta indispensável para que as decisões das organizações possam ser tomadas com segurança. Isto implica que as informações disponibilizadas sejam úteis e confiáveis para seus usuários. Nesse sentido, torna-se de extrema importância assegurar a qualidade da informação contábil, pois esta influencia a alocação de recursos, bem como a distribuição de riqueza entre os diversos agentes econômicos.

Dechow e Schrand (2004) consideram que a maior persistência de resultados é uma definição significante para qualidade dos resultados, somente se os resultados verdadeiramente refletirem o desempenho durante o período e se o desempenho do período corrente persistir nos períodos futuros.

Lopes e Martins (2005) consideram que as informações contábeis sofrem influência direta dos administradores e agentes em virtude de interesses pessoais decorrentes de mecanismos de remuneração, contratos estabelecidos, concorrência, legislação societária, dentre outros. Nesse sentido, a conduta das pessoas, sob a perspectiva de seu comportamento, gera reflexos nos padrões de conduta das empresas.

Dentro dessa linha de raciocínio, é oportuna a abordagem de Nash (2001) que, analisando as implicações éticas de uma orientação voltada para o resultado do balanço, diz que quando o lucro torna-se o propósito dominante, ele não é apenas priorizado, mas pode facilmente dominar a forma da tomada de decisão das pessoas. Isso se contrapõe à questão da ética empresarial, que estabelece que o comportamento ético seja o caminho para a obtenção de lucro com respaldo moral, como considera Moreira (2002, p. 31), dizendo que "o comportamento ético por parte da empresa é esperado e exigido pela sociedade". Esta impõe que a empresa aja com ética em todos os relacionamentos, especialmente com investidores, clientes, fornecedores, competidores e seu mercado, empregados, governo e público em geral. 
Ainda de acordo com Nash (2001), os executivos têm basicamente dois tipos de preocupação no que se refere a ética. A primeira diz respeito ao efeito de adotar-se padrões morais elevados sobre os resultados financeiros da corporação. Nesse contexto ser ético tem necessariamente um custo associado. A segunda preocupação está ligada ao temor de que a adoção de padrões não-éticos pelos empregados venha a se constituir em um passivo financeiro caso tais padrões cheguem a público.

A esse respeito, Hansen e Mowen (2003, p.40) dizem que "o objetivo da maximização do lucro deve ser limitado pelo requisito de que os lucros sejam obtidos por meios legais e éticos".

Wells e Spinks (1998, p.142) dizem que a linha divisória entre as ações éticas e as antiéticas está longe de ser clara. Para os autores, "no complexo mundo dos negócios de hoje, as pessoas que querem ser éticas podem não saber exatamente que ações terão resultados éticos e quais não." Essa questão é acentuada em um mercado cada vez mais competitivo, onde os recursos são escassos e os investidores disputados por um número cada vez mais crescente de empresas. Este cenário de competição acirrada, nas palavras de Wells e Spinks (1998), impede que as empresas sejam conservadoras em suas definições de comportamento ético. Segundo Lopes (2002, p.42) "a idéia geral do conservadorismo é fornecer informações mais confiáveis aos investidores por meio de demonstrações que não sejam excessivamente otimistas".

Entretanto, qual é o significado de ética? Conforme Ferreira (1999, p.848-849), ética vem do latim ethica e corresponde aos "Estudos dos juízos de apreciação referentes à conduta humana suscetível de qualificação do ponto de vista do bem e do mal, seja relativamente a determinada sociedade, seja de modo absoluto".

A ética é construída socialmente no coletivo. Conforme Moreira (2002) a existência de outros membros da mesma espécie compartilhando o mesmo espaço é que explica e legitima a existência de uma ética a ser seguida. Isaiah Berlin (1991) aponta para a impossibilidade de um bloco de valores morais fixos e válidos para todos. A diversidade conduz à criação de valores próprios em cada sociedade. Por outro lado, embora com valores distintos, é possível que um povo compreenda e respeite os valores dos outros.

\subsection{Características qualitativas da informação contábil}

Em 1961 foi criado um grupo de estudos contábeis para assessorar as autoridades da comunidade européia, propiciando maior discussão e renovação de assuntos contábeis. Este movimento evoluiu para a criação em 1973, do International Accounting Standard Committee (IASC). Em $1^{\circ}$ de abril de 2001 o IASC transformou-se no IASB (Internacional Accounting Standards Board), sendo suas normas denominadas de IFRS (International Financial Reporting Standards). O IASB é um órgão independente, do setor privado, para o estudo de padrões contábeis. É formado por um Conselho de Membros, constituído por representantes de mais de 140 entidades de classe de todo o mundo, inclusive do Brasil, representado pelo Ibracon e pelo Conselho Federal de Contabilidade (NIYAMA; SILVA, 2008).

De acordo com a constituição do IASB, seus objetivos são:

$>$ Desenvolver, no interesse público, um único conjunto de normas contábeis globais de alta qualidade, inteligíveis e exeqüíveis, que exijam informações de alta qualidade, transparentes e comparáveis nas demonstrações contábeis e em 
outros relatórios financeiros, para ajudar os participantes do mercado de capital e outros usuários em todo o mundo a tomar decisões econômicas;

$>$ Promover o uso e a aplicação rigorosa dessas normas;

$>$ Promover a convergência entre as normas contábeis locais e as Normas Internacionais de Contabilidade de alta qualidade.

Um dos principais benefícios pretendidos pelo IASB é de que seja possível a comparação das informações contábeis produzidas pelas empresas situadas em países distintos, permitindo, assim, a compreensão e a interpretação dos dados gerados por entidades de diferentes economias e tradições. (NIYAMA; SILVA, 2008).

Neste contexto, o IASB edita em sua estrutura conceitual, dentre outros componentes, as características qualitativas das demonstrações financeiras que representam as propriedades necessárias à informação para torná-la útil. As quatro principais características qualitativas são: compreensibilidade, relevância, confiabilidade e comparabilidade.

Compreensibilidade: segundo o CPC (2008), uma qualidade essencial das informações apresentadas nas demonstrações contábeis é que elas sejam prontamente entendidas pelos usuários. Para esse fim, presume-se que os usuários tenham um conhecimento razoável dos negócios, atividades econômicas e contabilidade e a disposição de estudar as informações com razoável diligência.

$>$ Relevância: segundo Hendriksen e Van Breda (2009), a informação é relevante quando afeta metas e decisões. O FASB (SFAC 2) definiu o termo como sendo a capacidade que a informação teria de "fazer diferença" numa decisão. O FASB (SFAC 2) argumentou ainda, que esta "diferença" tem um valor preditivo e um valor como feedback. O valor preditivo é a qualidade da informação que ajuda os usuários a aumentarem a probabilidade de prever corretamente o resultado de eventos passados ou presentes. Já o valor como feedback diz respeito à confirmação ou correção de expectativas anteriores.

$>$ Confiabilidade: segundo Hendriksen e Van Breda (2009, p.99), a confiabilidade é a "qualidade que garante uma informação razoavelmente livre de erro e viés e que represente fielmente o que visa representar." Ainda conforme os autores, a confiabilidade é função de fidelidade de representação, verificabilidade e neutralidade. Para que alguém confie em informações, é essencial que elas representem fielmente os fenômenos que pretende representar, é a função de fidelidade de representação. A verificabilidade é o atributo da informação que permite a indivíduos qualificados, trabalhando independentemente um do outro, chegar a medidas ou conclusões essencialmente iguais, a partir do exame da mesma evidência. A neutralidade quer dizer que não há viés na direção de um resultado pré-determinado.

> Comparabilidade: segundo o CPC (2008), os usuários devem poder comparar as demonstrações contábeis de uma entidade ao longo do tempo, a fim de identificar tendências na sua posição patrimonial e financeira e no seu desempenho. Os usuários devem também ser capazes de comparar as demonstrações contábeis de diferentes entidades a fim de avaliar a sua posição patrimonial e financeira, o desempenho e as mutações na posição financeira. 
A confiabilidade como característica qualitativa da informação contábil impediria o uso do gerenciamento de resultados, pois através da neutralidade, independente da assimetria informacional, as informações contábeis não seriam direcionadas a atingir um objetivo específico, e sim, demonstrar a realidade da empresa.

\section{Metodologia}

Em virtude do objetivo proposto, o presente estudo caracteriza-se como descritivo. Segundo Cervo, Bervian e Silva (2007, p.61), "a pesquisa descritiva observa, registra, analisa e correlaciona fatos ou fenômenos do mundo físico e especialmente do mundo humano (variáveis) sem manipulá-los". Gil (1999) complementa que a pesquisa descritiva descreve característica de uma determinada população ou fenômeno ou o estabelecimento de relações entre variáveis.

A importância da pesquisa descritiva para a contabilidade é iminente diante da necessidade de esclarecimento de determinadas características ou aspectos inerentes à área contábil. Segundo Andrade (2006), inclui-se entre as pesquisas descritivas a maioria daquelas desenvolvidas nas ciências humanas e sociais; as pesquisas de opinião, mercadológicas, os levantamentos socioeconômicos e psicossociais.

Para o desenvolvimento de uma pesquisa, também se torna necessário o seu delineamento. Desta forma, utilizou-se a pesquisa bibliográfica. Para Martins e Theófilo (2007), a pesquisa bibliográfica tem como finalidade principal explicar e discutir um assunto, tema ou problema com base em referências publicadas. Segundo Gil (1999) a principal vantagem da pesquisa bibliográfica reside no fato de que possibilita ao pesquisador a observação de uma diversidade de fenômenos e opiniões sobre o tema pesquisado. Segundo Cervo, Bervian e Silva (2007) a pesquisa bibliográfica procura explicar um problema a partir de referências teóricas publicadas em artigos, livros, dissertações e teses. Busca-se conhecer e analisar as contribuições culturais ou científicas do passado sobre determinado assunto.

O questionário foi utilizado para a coleta de dados, que conforme Gil (1999) é uma técnica de investigação composta por um número mais ou menos elevado de questões apresentadas por escrito às pessoas, tendo como objetivo o conhecimento de suas opiniões, crenças, sentimentos, interesses, expectativas, situações vivenciadas. Para Martins e Theófilo (2007) trata-se de um conjunto ordenado e consistente de perguntas a respeito de variáveis e situações que se deseja medir ou descrever.

Para tanto, usou-se uma amostra intencional dos alunos do curso de mestrado em Ciências Contábeis ingressantes em 2009 nas seguintes instituições: Universidade de São Paulo (USP), Universidade Federal de Minas Gerais (UFMG), Universidade Federal do Rio de Janeiro (UFRJ) e Universidade do Vale do Rio dos Sinos (UNISINOS). Os questionários foram enviados durante o mês de julho/09 por e-mail, sendo retornados e validados 20 questionários de um total de 60 alunos, até a data de 06/08/09. Para análise dos dados coletados, também foi utilizado o software de pesquisas www.encuestafacil.com .

Para documentar as opiniões dos alunos selecionados sobre o gerenciamento de resultados, utilizou-se o questionário desenvolvido por Bruns e Merchant (1989) com algumas alterações para a realidade brasileira. 
O questionário descreve dez práticas para gerenciamento de resultados, solicitando que cada respondente avalie cada questão escolhendo uma percepção dentro de uma escala de cinco pontos, a saber: i) prática ética; ii) prática questionável; iii) pequena infração; iv) infração grave; e, v) prática antiética.

\section{Resultado e Análise dos Dados}

O objetivo dessa sessão é documentar e avaliar os julgamentos dos entrevistados. Inicialmente, há, no Quadro 1, a descrição do perfil dos entrevistados com as características de idade, curso de graduação, outra titulação além da graduação e o estado civil.

Observa-se que $55 \%$ dos entrevistados estão entre 20 e 30 anos, o que denota um perfil jovem dos mestrandos. Observa-se, também, que $85 \%$ dos entrevistados concluíram a graduação em Ciências Contábeis, dando continuidade com o mestrado na área de atuação inicial. Outra característica observada é que embora os mestrandos possuam entre 20 a 30 anos na sua maioria, há um percentual de $45 \%$ que já possui outra titulação além da graduação. Este perfil pode ser traduzido pela existência de um mercado cada vez mais competitivo, exigindo profissionais com maior conhecimento para tomada de decisão.

\section{Quadro 1: Perfil dos entrevistados}

\begin{tabular}{|l|c|l|c|c|c|}
\hline \multicolumn{2}{|c|}{ Idade } & \multicolumn{2}{c|}{ Curso de Graduação } & \multicolumn{2}{c|}{ Outra titulação? } \\
\hline De 20 a 30 anos & $55 \%$ & Administração & $10 \%$ & Sim & $45 \%$ \\
\hline De 31 a 40 anos & $25 \%$ & Ciências Contábeis & $85 \%$ & Não & $55 \%$ \\
\hline Acima de 40 anos & $20 \%$ & Outros & $5 \%$ & & \\
\hline
\end{tabular}

Fonte: Dados da pesquisa.

O quadro 2 abaixo mostra as questões evidenciadas no questionário juntamente com as distribuições das opiniões dos alunos entrevistados nesta pesquisa.

Quadro 2: Comparativo de julgamentos dos entrevistados

\begin{tabular}{|c|c|c|c|c|c|}
\hline & $\begin{array}{l}\text { 1.Prática } \\
\text { ética }\end{array}$ & $\begin{array}{c}\text { 2.Prática } \\
\text { questionável }\end{array}$ & $\begin{array}{l}\text { 3.Pequena } \\
\text { infração }\end{array}$ & $\begin{array}{l}\text { 4.Infração } \\
\text { séria }\end{array}$ & $\begin{array}{l}\text { 5.Prática } \\
\text { antiética }\end{array}$ \\
\hline $\begin{array}{l}\text { 1. Redução de P\&D para cálculo de } \\
\text { compensações salariais baseadas em } \\
\text { medidas contábeis }\end{array}$ & $5 \%$ & $55 \%$ & $5 \%$ & $35 \%$ & 0 \\
\hline 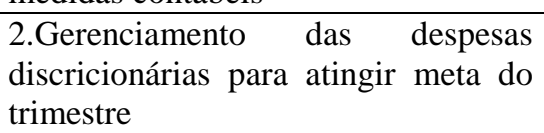 & $10 \%$ & $35 \%$ & $15 \%$ & $35 \%$ & $5 \%$ \\
\hline $\begin{array}{l}\text { 3.Gerenciamento das } \\
\text { discricionárias para atingir meta } \\
\text { anual }\end{array}$ & $10 \%$ & $20 \%$ & $15 \%$ & $45 \%$ & $10 \%$ \\
\hline $\begin{array}{l}\text { 4.Emissão de notas fiscais para } \\
\text { elevar o resultado do último mês do } \\
\text { ano. Tais notas seriam canceladas } \\
\text { posteriormente. }\end{array}$ & 0 & 0 & $10 \%$ & $30 \%$ & $60 \%$ \\
\hline $\begin{array}{l}\text { 5.Redução do lucro através de } \\
\text { constituição de provisão para perdas } \\
\text { com obsolescência dos estoques. }\end{array}$ & 0 & $20 \%$ & $30 \%$ & $15 \%$ & $35 \%$ \\
\hline $\begin{array}{l}\text { 6.Aumento do lucro através } \mathrm{de} \\
\text { reversão de provisão para perdas com }\end{array}$ & 0 & $25 \%$ & $20 \%$ & $35 \%$ & $20 \%$ \\
\hline
\end{tabular}


Marleide C. de Oliveria, Vagner Antonio Marques, Jacqueline V. Alves da Cunha e Poueri do Carmo Mario

\begin{tabular}{|l|l|l|l|l|l|}
\hline obsolescência dos estoques. & & & & & \\
\hline $\begin{array}{l}\text { 7.Reversão de toda provisão possível } \\
\text { para elevar o resultado em virtude de } \\
\text { emissão de novas ações no mercado. }\end{array}$ & $5 \%$ & $25 \%$ & $10 \%$ & $30 \%$ & $30 \%$ \\
\hline $\begin{array}{l}\text { 8. Estabilização do lucro em virtude } \\
\text { de aversão ao risco pelo investidor. }\end{array}$ & $15 \%$ & $25 \%$ & $10 \%$ & $35 \%$ & $15 \%$ \\
\hline $\begin{array}{l}\text { 9.Para Schipper (1989), o } \\
\text { gerenciamento de resultados pode ser } \\
\text { definido como uma intervenção } \\
\text { proposital no processo de elaboração } \\
\text { das demonstrações financeiras } \\
\text { externas, com a intenção de obter } \\
\text { algum benefício particular. }\end{array}$ & $5 \%$ & 0 & $5 \%$ & $15 \%$ & $75 \%$ \\
\hline $\begin{array}{l}\text { 10.As escolhas contábeis podem ser } \\
\text { ditadas de forma induzir credores a } \\
\text { assumirem postura favorável à } \\
\text { empresa. }\end{array}$ & $10 \%$ & $10 \%$ & $25 \%$ & $20 \%$ & $35 \%$ \\
\hline
\end{tabular}

Fonte: Dados da pesquisa.

O item 1 demonstra que a grande maioria dos entrevistados se sentiria desconfortável em aprovar uma redução de $\mathrm{P} \& \mathrm{D}$ somente para atingir um resultado que sirva de base para compensações salariais de executivos da empresa. Dechow e Sloan (1991) realizaram um estudo em que evidenciou que os executivos, em seus últimos anos no cargo, reduzem os gastos com pesquisa e desenvolvimento, com intuito de aumentar os lucros. Eles argumentam que esse comportamento é consistente com a natureza dos contratos de remuneração e seus pequenos horizontes de tempo.

Os itens 2 e 3 revelam que o período de tempo em que ocorrem os efeitos do gerenciamento de resultados afeta o julgamento dos entrevistados. Em geral, o adiamento de despesas discricionárias para cumprir as metas anuais foi considerado mais grave do que o adiamento para cumprimento das metas trimestrais.

O item 4 demonstra que $60 \%$ dos entrevistados consideram o procedimento de emissão de notas sem a respectiva venda e seu posterior cancelamento como prática antiética. Neste item, não houve nenhum respondente que o avaliou como ético ou como questionável, sendo o percentual crescente de pequena infração a prática antiética. Para Ferreira et al. (2012), é esperado que o gestor, de maneira oportunista, maximize sua utilidade mesmo que isso resulte em prejudicar a qualidade da informação divulgada.

Os itens 5 e 6 demonstram que os acadêmicos entrevistados não consideram como prática ética o uso das provisões para o gerenciamento de resultados. Ocorre uma distribuição de opiniões julgando desde prática questionável até a prática antiética. Contudo, existem estudos que comprovam a utilização de provisões no gerenciamento de resultados. McNichols et al. (1988) buscaram verificar se os diretores de empresas financeiras manipulam os resultados pelo uso da provisão de devedores duvidosos. Proporcionaram uma visão alternativa de pesquisa ao focalizar sua análise em accruals específicos.

Em relação ao item 7, embora apenas 5\% dos entrevistados considerem uma prática ética o gerenciamento de resultados para elevar o resultado no momento de emissão de ações, o estudo de Teoh et al. (1998) possui evidências que indicam que as empresas possuem accruals relativamente altos nos anos próximos à primeira subscrição de ações, o que explica 
o fato de essas empresas terem desempenho abaixo do mercado nos anos subseqüentes ao lançamento.

A prática de estabilização do lucro em virtude da aversão ao risco pelo investidor (item 8) apresentou o maior percentual de julgamento de prática ética (15\%). Tal índice pode ser justificado porque as empresas que tem oscilações demasiadamente altas nos seus resultados acabam ficando em segundo plano no momento dos investidores escolherem em quem investir, já que fortes oscilações demonstram uma dificuldade de se manter determinado resultado. Frente a essa necessidade ímpar dos investidores, a opção por uma empresa mesmo que com lucro menor, mas com resultados estáveis acaba sendo válida. Contudo, Hendriksen e Van Breda (2009) afirmam que a estabilização dos lucros "esconde" o verdadeiro resultado da empresa.

O item 9 representa uma definição do gerenciamento de resultados dada por Schipper (1989). Os entrevistados julgaram uma prática antiética (75\%) quando ocorre o gerenciamento para benefício particular. Porém, ocorreu uma divergência de julgamento entre a definição teórica e a prática desta mesma definição. $\mathrm{O}$ item 1 representa exatamente a definição dada por Schipper (1989), porém por estar convertida para uma atividade da empresa, não obteve nenhum julgamento de prática antiética.

Para Schipper (1989), o gerenciamento de resultados pode ser definido como uma intervenção proposital no processo de elaboração das demonstrações financeiras externas, com a intenção de obter algum benefício particular.

Segundo Healy e Wahlen (1999) existem alguns incentivos que levam os gestores a gerenciar resultados, entre eles o de auferir limites de crédito e melhores condições de financiamento, assim como para orientar cláusulas restritivas ou de proteção aos credores (item 10). Houve uma distribuição entre os entrevistados, sendo que $10 \%$ aceitaram tal prática como ética e $35 \%$ como uma prática antiética.

Parfet (2000) afirma que existe gerenciamento benigno de lucros, que consiste em tomadas de decisões operacionais para garantir o cumprimento de metas de lucros, tais como concessão de descontos para antecipar transações que ocorreriam normalmente no período seguinte. Na sua concepção, alcançar resultados estáveis e manter a taxa de crescimento dos lucros por meio de um bom planejamento não é ilegal ou antiético. É sinal de habilidade e excelência que o mercado procura e recompensa.

Um importante estudo foi realizado no Brasil por Sancovschi e Matos (2003) que expõem o pensamento médio de gestores e contadores acerca da prática de gerenciamento de resultados, a partir de pesquisas qualitativas realizadas no Brasil e nos Estados Unidos, destacando-se as seguintes conclusões:

a) Nenhuma das práticas - operacional ou contábil - foi julgada unanimemente ética ou antiética.

b) Os entrevistados consideraram que gerenciar lucros mediante a tomada de decisões operacionais é eticamente mais aceitável do que gerenciá-los mediante a escolha de procedimentos contábeis específicos.

c) Os contadores entrevistados nos Estados Unidos discriminaram com mais clareza as manipulações contábeis das manipulações operacionais do que os contadores entrevistados no Brasil. 


\section{Considerações Finais}

O presente estudo teve como objetivo, analisar o julgamento dos alunos de mestrado acerca do gerenciamento de resultados. Na análise dos dados coletados, nenhuma prática foi totalmente considerada como ética ou antiética. A prática considerada em maior percentual como antiética é quando ocorre o gerenciamento de resultados para obtenção de benefício particular (75\% consideraram como antiética). Esse resultado pode ser atribuído ao fato de que a Contabilidade não se insere no campo das ciências exatas. A liberdade para avaliar e decidir, é, e sempre será, fundamental para o adequado desempenho dessas atividades.

Pode-se argumentar que os julgamentos emitidos em relação às decisões tomadas para atingir determinado resultado sejam fortemente influenciados pelo uso generalizado de sistemas de controle financeiro para avaliar o desempenho dos gerentes e das unidades pelas quais eles são responsáveis. Não obstante a existência de outras medidas de desempenho, os gestores e as empresas ainda são avaliados em função do lucro auferido em curto prazo.

Bruns e Merchant (1990) recomendaram (1) que os administradores das empresas definissem padrões contábeis e operacionais mais claros e obrigassem todos a respeitá-los; (2) que o controle das manipulações operacionais fosse delegado aos gerentes operacionais; e, (3) que se fomentasse nas empresas, e fora delas, uma cultura que valorizasse a administração para a excelência operacional em vez de incentivar o alcance de objetivos quantitativos, financeiros ou não.

Fischer e Rosenzweig (1994) propuseram (1) a realização de seminários para a sensibilização de administradores e contadores; (2) a revisão das normas de seleção e recrutamento de funcionários nas empresas; (3) a criação de códigos de ética nas empresas que contemplassem especificamente a escolha de normas contábeis e a tomada de decisões operacionais; e, (4) a monitoração permanente das decisões operacionais nas empresas.

Segundo Sancovschi e Matos (2003) as escolhas de práticas contábeis para cumprir objetivos de lucro representam desvios de conduta dos gestores, que prejudicam tanto os interessados em empresas específicas, como os demais participantes do mercado de capitais. Portanto, elas devem ser evitadas, por meio de permanente avaliação das normas que regem a elaboração das demonstrações financeiras, pela implantação e manutenção de normas de conduta que estabeleçam os direitos e responsabilidades de todos os participantes do mercado de ações, e de mecanismos de arbitragem para dirimir dúvidas, acertar disputas entre participantes e punir os transgressores; e, no âmbito das empresas, por meio da implantação de sistemas de controle apropriados.

\section{Referências}

ACKER, M.D.; GIACOMINO, D.; BELlOVARY, L.J. Earnings Management and Its Implications: Educating the Accounting Profession. The CPA Journal. August, 2007. Disponível em: http://www.nysscpa.org/cpajournal/2007/807/essentials/p64.htm. Acess em: 08 nov. 2012.

ANDRADE, Maria Margarida. Introdução à metodologia do trabalho científico. 7. ed. São Paulo: Atlas, 2006. 
BERLIN, Isaiah. Limites da utopia - capítulos da história das idéias. São Paulo: Cia. das Letras, 1991.

BRUNS, W.; MERCHANT, K. Ethics test for everyday managers. Harvard Business Review, p. 220-221, mar./apr. 1989.

BRUNS, W.; MERCHANT, K., The dangerous morality of managing earnings. Management Accounting, p. 21-25, aug. 1990.

CERVO, Amado L.; BERVIAN, Pedro A.; Da Silva, Roberto. Metodologia científica. 6. ed. São Paulo: Pearson Prentice Hall, 2007.

COLAUTO, Romualdo D.; BEUREN, Ilse M. A identificação de accruals no sistema de lucro contábil: o caso Parmalat Brasil. In: ENCONTRO NACIONAL DOS PROGRAMAS DE PÓS GRADUAÇÃO EM ADMINISTRAÇÃO, 28., 2004, Curitiba/PR. Anais... Curitiba: Encontro da ANPAD, 2004. CD-ROOM.

COMISSÃO DE VALORES MOBILIÁRIOS (CVM). Ofício-circular CVM/SNC/SEP N ${ }^{\circ}$ $01 / 2007$. Orientações gerais sobre procedimentos a serem observados pelas companhias abertas, 2007.

COMITÊ DE PRONUNCIAMENTOS CONTÁBEIS (CPC). Estrutura conceitual para a elaboração e apresentação das demonstrações contábeis, 2008.

CUPERTINO, César Medeiros. Gerenciamento fraudulento de resultados contábeis: o caso Banco Nacional. In: ENCONTRO NACIONAL DOS PROGRAMAS DE PÓS GRADUAÇÃO EM ADMINISTRAÇÃO, 28., 2004, Curitiba/PR. Anais... Curitiba: Encontro da ANPAD, 2004. CD-ROOM.

DECHOW, Patrícia. M.; DICHEV, I. D. The quality of accruals and earnings: the role of accrual estimation errors. The Accounting Review, v. 77, p. 35-59, 2002.

DECHOW, Patrícia. M.; SCHRAND, Catherine M. Earnings quality. Charlottesville (Virginia): CFA Institute, 2004.

DECHOW, Patricia M.; SLOAN, Richard G. Executive incentives and the horizon problem: An empirical investigation. Journal of Accounting and Economics, v.14, n.1, p.51-59, mar. 1991.

DECHOW, Patricia M.; SLOAN, Richard G.; SWEENEY, Amy P. Detecting earnings management. The Accounting Review, v. 70, n. 2, 1995.

FERREIRA, Aurélio Buarque de Holanda. Novo Aurélio século XXI: o dicionário da língua portuguesa. Rio de Janeiro: Nova Fronteira, 1999.

FERREIRA, Felipe Ramos; MARTINEZ, Antonio Lopo; COSTA, Fábio Moraes Da; PASSAMANI, Renato Rovetta. Book-tax differences e gerenciamento de resultados no mercado de ações do Brasil. Revista de Administração de Empresas, v. 52, n. 5, p. 488-501, 2012.

FIPECAFI. Manual de Contabilidade das Sociedades por ações. 7 ed. São Paulo: Atlas, 2009.

FISCHER, M.; ROSENZWEIG, K. Is managing earnings ethically acceptable? Management Accounting, v. 75, n. 9, p. 31-34, mar. 1994. 
FORMIGONI, H.; PAULO, E.; PEREIRA, C.A. 2007. Estudo sobre o gerenciamento de resultados contábeis pelas companhias abertas e fechadas brasileiras. In: CONGRESSO DA ASSOCIAÇÃO NACIONAL DOS PROGRAMAS DE PÓSGRADUAÇÃO EM CIÊNCIAS CONTÁBEIS, 1., 2007, Gramado/RS. Anais... Gramado, ANPCONT, 2004. CD-ROM.

GIL, Antônio C. Métodos e técnicas de pesquisa social. São Paulo: Atlas, 1999.

HANSEN, Don R.; MOWEN, Maryanne M. Gestão de custos. São Paulo: Pioneira Thomson Learning, 2003.

HEALY P. M.; WAHLEN, J. M. A review of the earnings management literature and its implications for standard setting. Accounting Horizons, v. 13, n. 4, p. 365-383, 1999.

HENDRIKSEN, Eldon S.; VAN BREDA, Michael F. Teoria da Contabilidade. São Paulo: Atlas, 2009.

IUDICÍBUS, Sérgio de. Teoria da contabilidade. 7. ed. São Paulo: Atlas, 2004.

JONE, JENNIFER J. Earnings management during import relief investigations. Journal of Accounting Research. Chicago, v. 29, n. 2, p. 193-228, autumn, 1991.

KANG, Sok-Hyon; SIVARAMAKRISHNAN, K. Issues in testing earnings management: an instrumental variable approach. Juornal of Accounting Research, v. 33, n. 2, 1995.

LOPES, Alexsandro B. A informação contábil e o mercado de capitais. São Paulo: Pioneira Thomson Learning, 2002.

LOPES, Alexsandro B.; MARTINS, Eliseu. Teoria da Contabilidade: uma nova abordagem. São Paulo: Atlas, 2005.

MARTINEZ, A.L. "Gerenciamento" dos Resultados Contábeis: estudo empírico das companhias abertas brasileiras. 2001. 153f. Tese (Doutorado em Controladoria e Contabilidade). Curso de Pós-Graduação em Controladoria e Contabilidade, Universidade de São Paulo - FEA/USP, São Paulo, 2001.

MARTINS, Gilberto de A.; THEÓPHILO, Carlos R. Metodologia da Investigação Científica para Ciências Sócias Aplicadas. São Paulo: Atlas, 2007.

MATOS, Felipe Faissol J.; SANCOVSCHI, Moacir. Earnings management: the case of Iucent Technologies. In: SEMINÁRIO USP DE CONTROLADORIA E CONTABILIDADE, 3., 2003, São Paulo/SP. Anais... São Paulo: USP, 2003. CD-ROOM.

McNICHOLS, Maureen; WILSON, G. Peter; DeANGELO, Linda. Evidence of earnings management from the provision for bad debts. Journal of Accounting Research. v. 26, p.1-31, supplement, 1988.

MOREIRA, Luís Fernando. A respeito de ética e finanças. RAE-eletrônica, v. 1, n. 2, jul/dez. $2002 . \quad$ Disponível em http://www.rae.com.br/eletronica/index.cfm?FuseAction=Artigo \&ID=390\&Secao=FINANÇAS2

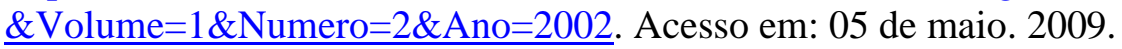

MUSSOLINI, Luiz Fernando. A função social da Contabilidade. Revista Brasileira de Contabilidade, Brasília, v. 23, n. 89, p.72-80, nov. 1994. 
NARDI, Paula C. C. Gerenciamento de resultados contábeis e a relação com o custo da dívida das empresas brasileiras de capital aberto. 2008. 126f. Dissertação (Mestrado em Controladoria e Contabilidade). Curso de Pós-Graduação em Controladoria e Contabilidade, Universidade de São Paulo - FEA/USP Ribeirão Preto, São Paulo, 2008.

NASH, Laura L. Ética nas empresas. São Paulo: Makron Books, 2001.

NIYAMA, Jorge K.; SILVA, César A. T. Teoria da Contabilidade. São Paulo: Atlas, 2008;

PARFET, W. Accounting subjectivity and earnings management: a preparer perspective. Accounting Horizons, v.14, n.4, p. 481-488, dec. 2000.

PAULO, Edílson; MARTINS, Eliseu. Análise da Qualidade das Informações Contábeis nas Companhias Abertas. In: ENCONTRO NACIONAL DOS PROGRAMAS DE PÓS GRADUAÇÃO EM ADMINISTRAÇÃO, 31., 2007, Rio de Janeiro/RJ. Anais... Rio de Janeiro: RJ, 2007. CD-ROOM.

RODRIGUES, Adriano. Gerenciamento da Informação Contábil e regulação: evidências no mercado brasileiro de seguros. 2008. 150f. Tese (Doutorado em Controladoria e Contabilidade). Curso de Pós-Graduação Controladoria e Contabilidade, Universidade de São Paulo - FEA/USP, São Paulo, 2008.

SANCOVSCHI, Moacir; MATOS, Felipe F. J. de. Gerenciamento de lucros: que pensam administradores, contadores e outros profissionais de empresas no Brasil?. Revista de Administração Contemporânea, v.7, n. 4, p. 141-161. 2003.

SCHIPPER, Katherine. Commentary on earnings management. Accounting horizons. Sarasota: v.3, n.4, p. 91-102, dec. 1989.

TEOH, Siew; WELCH, Hong; WONG, Ivo. Earnings management and the underperformance of seasoned equity offerings. Journal of Financial Economics, v.50, n.1, p. 63-99, out. 1998.

TORRES, D.; BRUNI, A. L.; CASTRO, M.A.R.; MARTINEZ, A.L. Estrutura de Propriedade e Controle, Governança Corporativa e o Alisamento de Resultados. Revista Contemporânea de Contabilidade (UFSC), v. 7, n. 13, p. 11-34, 2010.

WELLS, Barron; SPINKS, Nelda. Ética de cima para baixo. In: HSM Management, ano 2, n. 7, p. 142-146, mar/abr. 1998. 
